\title{
Caring Relationships in Home-Based Nursing Care - Registered Nurses' Experiences
}

\author{
Britt-Marie Wälivaara ${ }^{*}$, Stefan Sävenstedt and Karin Axelsson
}

Division of Nursing, Department of Health Science, Luleå University of Technology, SE-971 87 Luleå, Sweden

\begin{abstract}
The caring relationship between the nurse and the person in need of nursing care has been described as a key concept in nursing and could facilitate health and healing by involving the person's genuine needs. The aim of this study was to explore registered nurses' experiences of their relationships with persons in need of home-based nursing care. Individual interviews with nurses ( $\mathrm{n}=13$ registered nurses and 11 district nurses) working in home-based nursing care were performed. A thematic content analysis was used to analyze the transcribed interviews and resulted in the main theme Good nursing care is built on trusting relationship and five sub-themes, Establishing the relationship in homebased nursing care, Conscious efforts maintains the relationship, Reciprocity is a requirement in the relationship, Working in different levels of relationships and Limitations and boundaries in the relationship. A trusting relationship between the nurse and the person in need of healthcare is a prerequisite for good home-based nursing care whether it is based on face-to-face encounters or remote encounters through distance-spanning technology. A trusting relationship could reduce the asymmetry of the caring relationship which could strengthen the person's position. The relationship requires conscious efforts from the nurse and a choice of level of the relationship. The trusting relationship was reciprocal and meant that the nurse had to communicate something about themself as the person needs to know who is entering the home and who is communicating through distance-spanning technology.
\end{abstract}

Keywords: Relationship, home-based nursing care, registered nurses, experiences, distance-spanning technology, interviews, thematic content analysis.

\section{BACKGROUND}

One of the key concepts in nursing is the caring relationship between the nurse and the person in need of care, and the care relationship together with the task to be undertaken form the core of nursing care [1,2]. The care relationship could be understood, according to Aristotelian description, in a poesis perspective and means that there is a goal of nursing action outside the relationship. The caring relationship could also be described from a praxis perspective where there is no goal of nursing actions beyond the relationship itself. In other words a poesis perspective emphasizes the goal while a praxis perspective emphasizes the process leading up to the goal $[2,3]$.

A systematic literature review [4] shows that the concepts of interaction, communication and relationship are not clearly defined in nursing literature. The concepts are close to each other and strongly intertwined and are sometimes used interchangeably. In the literature there are also different concepts of relationships for example, care relationships, nursing relationships, interpersonal relationships, therapeutic relationships and caring relationships and it is not always clear what the differences are and also these concepts are sometimes used interchangeably.

*Address correspondence to this author at the Division of Nursing, Department of Health Science, Luleå University of Technology, SE-971 87 Luleå, Sweden; Tel: +46920 493848; Fax: +46 920 493850;

E-mail: britt-marie.valivaara@ltu.se
Kasén [5] argues that a care relationship could develop to be a caring relationship. In a caring relationship the whole person is included, which is physical, mental and spiritual aspects. The caring relationship could enable human growth. A caring relationship could be seen as a mutual relationship that requires trust between the both parties. Within the caring relationship the caregiver gives a promise of care and implicit promises of alleviation of suffering and also a promise of togetherness and personal contact [5]. The caring relationship can be understood as balancing between vulnerability and dignity i.e. decreasing vulnerability and maintaining dignity [6]. The caring relationship could also be understood as a relationship that facilitates health and healing by involving the person's genuine needs [7]. An uncaring relationship was described when the person was an object to be cared for and the caregiver performs the task. When the caring relationship is absent the person is left alone in their anxiety, pain and fear [5].

Løgstrup [8] considers that when two people enter a relationship with each other an ethical demand appears, which is related to the fact that we as human beings are interdependent. Naturally, we encounter each other with trust which is fundamental to all social intercourse. The trust makes us vulnerable when we expose ourselves to each other and trust means that we expect the other to preserve our dignity. During the encounter we have power and responsibility for each other as we hold each other's lives in our hands. The trust will persevere and the power will be used to promote the other's potential. 
In nursing care, maintaining a helping relationship is a way of caring for human needs. This caring relationship means that the nurse focus on needs, limitations and the potential of the person [9]. The nurses have to be authentic and adaptive to the person in need of care and the situation [4]. Good relationships might also improve persons' satisfaction with nursing care [10]. The professional relationship is an important aspect of nursing care and can have both positive and negative effects on persons' experiences of the nursing care [4] and quality care [7].

The relationship in nursing has been studied widely, particular in psychiatric care [11] and in palliative care [12,13]. A study [12] shows that nurses created a close relationship when caring for dying persons and the study also shows differences in nurses' experiences when caring for dying persons in hospital and in home care. In the hospital settings, the nurse had to provide the family with the opportunity to take part in the care of the person and in home care settings the nurse was invited to the family's daily life and their means of caring for the dying person. A realist review of literature [10] shows clearly the importance of the relationship between district nurses and persons in need of palliative care. It also shows that few studies explore what a relationship meant and what its purpose is to the nurse. Grandoz Gámez [9] emphasizes that the attention of nursing is determined by the uniqueness of the nurse who is caring, regardless of the context or the person cared for.

Since the relationship seems essential for the outcomes of the nursing care and also affects the person's experiences of received nursing care it is important to study the relationship further in home-based nursing care where the context of the relationships usually is different compared to hospital care. Another important reason for study the relationship further is that the literature has shown that care suffering arises from negative relationships despite the fact that it is supposed to promote health and well-being [14]. The nurse is responsible for the caring relationship and that the relationship turns out positive. The aim of this study was to explore registered nurses' experiences of their relationships with persons in home-based nursing care.

\section{METHODS}

A qualitative approach with individual interviews and a thematic content analysis were chosen for this study [15].

\section{Participants and Procedure}

Healthcare managers $(n=8)$ in four territories in the northern Sweden were contacted and gave their consent for the study. The healthcare managers were asked to name registered nurses (RNs) and district nurses (DNs) who had at least one year's experience of working in home-based nursing care, which was the inclusion criterion for the study. A total of $24 \mathrm{RNs}$ and $18 \mathrm{DNs}$ received letters with information about the study and they were asked to participate in an individual interview. Thirteen RNs and 11 DNs agreed to participate. All participants were female. Six RNs and six DNs declined to participate and five RNs and one DN did not reply. The participants were given written and verbal information about the study and that their participation was voluntary with possibility of withdrawing without any explanation at any time. Assurance was given that the presentation of the findings would be used in such a way that none of them as individuals could be recognized by others. The study was approved by the Regional Ethical Review Board in Umeå, Sweden (Dnr 2010-224-31M).

\section{Context and Concepts}

The four chosen territories represent one city area and three remote areas. In each territory both healthcare managers in primary healthcare and healthcare managers for social welfare services are responsible for home care service. This means that in the same territory, both county council and the municipality are responsible for healthcare. The DNs were employed by the county council and responsible for healthcare in ordinary homes. The RNs were employed by the municipality and responsible for healthcare in sheltered housing. The DNs have no staff they can delegate assignments to and the RNs have enrolled nurses who they can supervise and delegate some assignments to. All participants had extensive experience of home visits as well as distance-spanning technology especially telephone contact, in their daily work in home-based nursing care. The policy in Sweden is that the most care should be carried out at the healthcare center, where DNs work, and only for special reasons DNs should make home visits. The RNs do not need a prescription but can decide when they make home visits. The participants had a large variation in the distance travelled to the person in need of healthcare at home. In present study the idea of a nurse is used and includes RNs and DNs. Primary nurse means a nurse who has primary responsibility for nursing care and healthcare for a person. Secondary nurse means a nurse who is responsible for but does not have primary responsibility for a person's nursing care and healthcare. Stand-in nurse means a registered nurse who is deputize for a primary nurse. The conception home includes ordinary homes and sheltered housing. In Sweden sheltered housing can be a residential home and a nursing home. Distance-spanning technology in the present study means a telephone, web camera and videoconferencing equipment. Selected concepts are based on our interpretation of the participants' descriptions and our knowledge of the organizations.

\section{Data Collection and Analysis}

Data was collected through open individual interviews. The nurses were asked to freely talk about the encounter in home-based nursing care and the interview questions for this study grew out of the nurses' argumentations about the need for encounters in order to establish and maintain a relationship and the importance of relationships in homebased nursing care. The narration was supported with follow-up questions and clarifying questions such as "You say that the relationship is important, can you explain and describe more?", "Can you give examples?", "What happened within the relationship in home-based nursing care?" [16]. According to the participant's wish, the interviews were carried out at the participant's home $(n=2)$, at the participant's place of work $(n=21)$ and at the interviewer's office $(n=1)$. The interviews were taperecorded and lasted for 60-90 minutes. The interviews were carried out by the first author between October 2010 and December 2010, except of one interview that was done in 
March 2011 in accordance with the participant's request. The interviews were transcribed verbatim.

The analysis started with a reading of the text several times to get a sense of the whole [17]. The interview text from the RNs and DNs were viewed as one text and was later divided into two main areas, relationship and encounter, which were identified in the text and analyzed separately. All interview text was the focus for analysis. The present study is an exploration of the relationship and the analysis of the encounter will be published elsewhere. The analysis continued with a thematic content analysis inspired by Berg (15], which meant that the text about relationship was read several times and then divided in meaning units and condensed. The condensed meaning units were sorted according to similarities and differences and the analysis process was stored in NVivo 9 which provides an audit trail from the original interview text during every single step of the analysis to the themes [18]. Text units were step-vice grouped into categories of content and merged into higher abstraction level. Finally, themes [15] and a main theme [19] were interpreted. To ensure trustworthiness in the analysis process the categories and themes were regularly compared with the original interview text and all authors took part in the process [15].

\section{RESULTS}

During the analysis both explicit and implicit themes were identified [15] that reflect dimensions of relationship in homebased nursing care. Altogether one main theme and five subthemes were identified (Table 1), where the main theme describes the thread of implicit meaning of the whole interview text [19]. Each sub-theme should be viewed as an interpretation of the content in part of the text. Metaphorically speaking the main theme is the warp that runs through the entire weave of content and the weft are sub-themes that represent different patterns in the weave [20].

Table 1. Main Theme $(n=1)$ and Sub-Themes $(n=5)$ Found in Nurses' Experiences of Relationships in HomeBased Nursing Care

\begin{tabular}{|c|c|}
\hline Main Theme & Sub-Themes \\
\hline \multirow[t]{5}{*}{$\begin{array}{l}\text { Good nursing care is built } \\
\text { on a trusting relationship }\end{array}$} & $\begin{array}{c}\text { Establishing the relationship in home- } \\
\text { based nursing care }\end{array}$ \\
\hline & $\begin{array}{c}\text { Conscious efforts maintain the } \\
\text { relationship }\end{array}$ \\
\hline & $\begin{array}{c}\text { Reciprocity is a requirement in the } \\
\text { relationship }\end{array}$ \\
\hline & Working in different levels of relationships \\
\hline & $\begin{array}{l}\text { Limitations and boundaries in the } \\
\text { relationship }\end{array}$ \\
\hline
\end{tabular}

\section{Good Nursing Care is Built on a Trusting Relationship}

It was obvious from the nurses' narrations that the relationship was important in home-based nursing care and both the person in need of care and the nurses were affected of the relationship. The relationship seemed to be the vehicle through which the nurses could approach and reach the persons in need of care and was essential and a prerequisite for providing good nursing care. In situations with superficial relationships there were experiences of nursing care where the person's needs were not met and a risk for harm occurred. Trust was an important component in a wellfunctioning relationship and could increase the sense of security, especially when the person was dependent on care. A trusting relationship could also contribute to make the person feel better. It seemed as the relationship in homebased nursing care was equally important regardless of which phase in life the person was in, palliative care or curative care. Nurses described that home visits and the relationship seemed to be of more importance for lonely persons with limited supporting social network.

\section{Establishing the Relationship in Home-Based Nursing Care}

The relationship in home-based nursing care was established by the first encounter and the nurse and the person had contact with each other and from there built the relationship. The first encounter and the first contact were characterized by normal socialization and were perceived as important, since it could affect the further development of the relationship between the nurse and the person. The first time nurses visit the person's home they entered as strangers and presented themselves by name and as a professional role. Entering the person's home meant acting to like a guest in respecting the person's conditions. Nurses tried in the first contact to read the person and sense if the person was ready for further contact and a relationship with the nurse. When the first encounter and contact developed well, a good relaxed relationship could be built where the nurse and the person got to know each other. Knowing each other also meant that the nurse still was professional but the conversation could be more personal without being private. The relationship was growing when nurses made home visits and gave support. The experience was that home visits could give a deeper and more intimate relationship than in hospital-based nursing care. The relationship at home meant that nurses were informed of more details and got a more comprehensive picture of the person's life story.

There were also barriers for a close relationship and it was obvious that each home visit and contact did not develop well. Examples given by the nurses of the barriers for the relationship were previous negative encounters with the nurse, the person's wish to maintain integrity and distance, and a threatening home environment and old family feuds. In situations where distance-spanning technology was used in the encounter it seemed that it was important to know each other's faces when the nurse and the person tried to establish a relationship through distance-spanning technology. When the nurse and the person had previous knowledge of each other and the relationship was established, remote communication could facilitate the maintenance of the relationship.

we have met, I know what you look like...well then it becomes an entirely different level [over the telephone], I think uh...if I have no face of the person I think I'm groping around... something I haven't really got control of RN8:63 


\section{Conscious Efforts Maintain the Relationship}

Relationships in home-based nursing care did not occur by itself and it required conscious efforts for both establishing and maintaining a working relationship. The effort meant, among other things, to prioritize the building and maintenance of relationships by nurses. An example was when nurses experienced during home visits lack of contact or the contact was not experienced as good, they made the effort to visit the person's home several times since the experience was that repeated contacts could facilitate and maintain a relationship. Usually it took time to reach a level where confiding occurred and patience was often necessary to develop the relationship. To make an effort to show humility, empathy, respect and treat the person well seemed to be the prerequisites for a good working relationship in home-based nursing care.

The nurses' experience was that the confidence that their presence in the home could contribute facilitated the relationship. The secure presence was characterized by reciprocity between the nurse and the person and gave an opportunity to share time together and being seen and confirmed. Being able to sit quietly together meant that the relationship had advanced. Reciprocity could be achieved when the person was allowed being involved in the person's own nursing care or when nurses showed interest and commitment to the person. Showing interest and commitment meant among other things listening, asking questions and touching. Based on nurses' descriptions it seems that commitment also meant finding a good balance between being personal and being professional. The already developed relationship could be maintained through home visits or by keeping in touch with each other through distance-spanning technology, such as phone calls.

you should not be stressed when you make contact and that...you may have patience too...you have to yes make several visits because it might not be as good the first times or become oh well contact or...but then you have to work on it $R N 9: 85$

and they can call and also I'm calling, I do that...many times when you don't do home visits you call and ask how it is...it's important that they know that they also can call...so that's also an option, I'm calling and we do so...we call and ask how things are and so on DN4:60

\section{Reciprocity is a Requirement in the Relationship}

The nurses experienced that reciprocity was a requirement for a good relationship, where the nurse and the person supported were interdependent and mutually contributed in order to have a working relationship. The relationship could work when there was a mutual giving and taking between the nurse and the person in need of care. The reciprocal relationship was stimulated by conversations where nurses avoided interviewing the person. The conversations were about other things than illness and problems and knowledge of people made it easier to find suitable topics of conversation. This kind of conversation meant that the person and the nurse opened up and had a more personal conversation. This meant that the roles of nurse and care receiver were less pronounced and were characterized by the nurses as being a professional friend. The experience was that reciprocity was hampered when too much focus was on the professional role and tasks. At the same time tasks could also open the door to the reciprocal relationship. The personal knowledge of people's situation and a reciprocal relationship could facilitate nurses' assessments in home-based nursing care both during home visits and via encounters through distance-spanning technology. There was an experience that there was a tendency that conversations via distance-spanning technology more often focused on the illness and was more task-oriented than face-to-face encounters and that affected the sense of reciprocity and community.

when I'm sitting down and talking to them...it's not as...it's really not as a district nurse but it's more like human to human DN10:65

I think that in order to get that feeling it's important to both give and take...do you understand...I have to give a little of myself but that means you have to do the same RN8:39

I think it's more difficult with...with a camera to get that feeling that here we are together and pondering RN10:69

\section{Working in Different Levels of Relationships}

The experience of the nurses was that they made a difference for the importance of relationship between the person for whom they were administratively responsible, i.e. a primary nurse, and others. The nurses prioritized the person that she had most contact with and those she felt responsible to solve problems for, answered questions, and those she knew well. When the person showed confidence and told the nurse about their thoughts and problems and the nurse could meet their needs, so that a deeper and special relationship occurs. The deeper relationship meant that nurses became more engaged, and reflected more extensive for the person and their situation, which also affected the relationship. The situation was very different when the nurses worked as a stand-in nurse and or a secondary nurse. In those situations the relationship could also work well but it was often at a different more shallow level compared with the relationship when they were the primary nurse.

I absolutely think without a relationship it will not work...you have to build a relationship with the person you should take care of in order to be able to provide the best care, because otherwise it becomes very superficial...you go in and take care of the wound and then out, by by DN2:55

as a stand-in nurse you're just in...one can really just get volatile relationships there...but I felt she...I know she would recognize me and talk if she saw me...yes so in some way we create...well some little a relationship to her anyway RN1:25 


\section{Limitations and Boundaries in the Relationship}

There were factors that limited the relationship in homebased nursing care. One example was limited time due to nurses' high workload, which meant that nurses sometimes had to cut down on time for building and maintaining relationships. Limited time could lead to a limitation of relationships and broken relationships. It was obvious that the relationship with the person to whom the nurse was a primary nurse was given a higher priority. Good communication was important for the relationship and when the language barrier occurred it was another limitation of the relationship.

The experience was that the relationships in home-based nursing care also needed some frames and boundaries. Examples of nurses' self-imposed restrictions were among other things when they knew the person in private or when they could sense that the relationship was not healthy for either the person or the nurse. The relationship was also restricted by nurses when the person came too close and the relationship tended to be too personal and private and they could sense the risk to lose their professionalism. The professional relationship meant being personal but not private and the nurses' challenge seems to be to manage the balance between a personal and private relationship.

but at the same time you should not uh...it must be a confident and a secure relationship...you should take time to listen and so on but at the same time you cannot let them eat you up either, you must be able to draw the line, now I have taken care of the wound, now I have listened for a while, we have talked now I have to leave though in a week I will be back again or whatever it might be DN6:47

\section{DISCUSSION}

The findings indicate that the nurses were aware of the importance of the caring relationship in home-based nursing care and they worked consciously to develop the relationship. The caring relationship in this study could be understood as a trusting relationship, which is needed in order to provide good nursing care at home. This is in line with Berg and Danielson's findings [21] that show that both nurses and persons in need of hospital care in a medical ward were aware that they were striving for trust through forming a caring relationship and they used their specific skills to form a caring relationship. The finding shows that a personal caring relationship could make trust possible and also that several encounters could create trust on which a relationship can be built. A concept analysis of nurse-patient trust [22] defines trust as the optimistic acceptance of a vulnerable situation, following careful assessment, in which the truster believes that the trustee has his best interest as paramount importance. In addition, Hagerty and Patusky [23] showed that the person in need of healthcare might trust the nurse in one area but not in another. A trusting relationship is one where the nurse cares for and about the person [24]. This is also in line with the nurses' experiences in present study. According to Hupcey, Penrod, Morse and Mitcham [25] the outcome of trust is an evaluation of the congruence between expectations of the trusted person, i.e. the nurse, and the nurse's actual behaviours.

In present study, the trusting relationship at home is, among other things, a reciprocal relationship that does not occur by itself and needs the nurses' to consciously work at. Kasén [5] argues that the caring relationship can never be fully reciprocal as this would mean that the person's suffering would not be alleviated. The caring relationship is inherently asymmetrical and means that the person with health problems is a suffering human and the nurse is caring and responsible. Buber [26] highlights that a fully reciprocal therapeutic relationship would be at the expense of its healing characteristics. The choice to embrace the approach I-Thou and entering the relationship and abandon the approach I-It [26] could be understood as an ethical choice [27] in home-based nursing care. On the other hand the asymmetry that exists in the caring relationship could potentially be unethical if it is not balanced with reciprocity [28]. According to the findings in present study it seems that the context of home-based nursing care encourages the reciprocal aspect of the relationship and reduces the asymmetry within the caring relationship. The encouragement of reciprocity in the caring relationship seems to relate to the fact that the nurse enters the home as a guest and has to balance between being personal, and in that encourage reciprocity, and being professional. This does not mean an equal relationship, and should not be confused with the ethical demand within the relationship [8].

Løgstrup [8] asserts that all human relationships are in some aspect reciprocal in that humans are interdependent and influence each other. Interdependence can be understood as what the nurse does for the person the nurse also does to herself. Despite the interdependence the nurse in home-based nursing care cannot, as a professional, demand to receive from the relationship as it is always an ethical relationship where what the nurse gets could be seen as a gift. Giving and receiving gifts could lead to confirmation of each other within the ethical relationship and not accept the other's gift may be perceived as a lack of confirmation [8]. Buber [29] asserts that the desire for confirmation and the ability to confirm others is fundamental to human life with others and being personal. We can assume that the nurse's ability to provide confirmation is an important part of building the relationship in home-based nursing care.

The findings of present study also indicate that nurses work in different levels of the relationship and closeness was not always the primary goal. Using the description by Buber [29] it can be described that the nurses had two movements, one to enter the relationship with the person in need of care and another to preserve a distance. The choice of the primary nurses in present study was to consciously chose to enter the relationship and work towards a deeper level of the relationship. This meant that the nurse had more contacts, was engaged with the person, knew the person well, and developed a common story. A common story, is according to Kasén [5], defined as the person's request for the alleviation of suffering and the nurse's answer to the request. The importance of a common story could be an argument for a higher continuity with the primary nurse in healthcare at home, in order to protect the caring relationship. 
In situations of being the secondary nurse and the standin nurse, the movement of preserving distance [29] often was the choice of the nurses in present study, where they consciously chose to work in a more shallow level of the relationship. This choice of a more distanced relationship in home-based nursing care could be understood as a way to respect the person's integrity when nurses knew that they could not continue with the nursing care and the relationship. We can assume that it could be experienced as unethical for a secondary nurse and a stand-in nurse to ask the person to share deeper feelings and then leave the person without any follow-up.

The choice of level in a relationship in home-based nursing care is also dependent on the will of the person in need of care. An example of this was described in a study by Ejneborn Looi and Hellzén [30]. Staff at municipal psychiatric group dwellings described some of their relationships with long-term psychiatric clients as characterized by distance. The distance was reflected in that the staff could not reach and get the contact with the client when clients did not invite them and refused the staff's support.

The findings in present study also indicate the presence of intentional and unintentional professional boundaries in the relationship, which according to Ejneborn Looi and Hellzén [30] occurred when the staff chose to adhere to their professional role and not be too personal with the clients [30]. Reasons for professional distance in a caring relationship could, according to Bergum and Dossetor [31], be fear of getting too involved or fear of not having the time to get involved at all. A standpoint of distance in a caring relationship means the risk of not being able to establish and build a trusting relationship with the person in need of nursing care at home and thereby no fruitful caring relationship.

A study [32] shows that time and geographical distance are important factors when building relationships between nurses and persons in home-based nursing care. Another study [33] shows that time and the continuity between the nurse and the person are preconditions for establishing a trusting relationship. It is especially the first visit that requires time to build the base for a trusting relationship. It is also important that the person can reach the nurse by a telephone call. Present study shows that the trusting relationship could be maintained through contacts by distance-spanning technology which also meant that the continuity could be supported. Knowing each other's faces seems to be important for trust when using distance-spanning technology. Lévinas [34] asserts that the relationship to the other's face is an ethical relationship with a particular responsibility. This means that nurses are responsible in home-based nursing care to protect the trusting relationship when different technology applications for distance communications are used in contemporary home-based care. A previous study [35] shows that when the person trusts the DNs they also felt confident with the use of technology in healthcare at home. The development of different distancespanning technologies can open up new solutions to perform care and maintain relationships at home [36,37]. As a reaction to this development of increased use of distancespanning technology, Meleis [1] argues that many theorists in nursing are going back to basics in human relationships, where the sharing of information during situations of health and illness and the interaction is a tool for building relationships. This emphasis on the importance of basic human interaction highlights the importance when implementing distance-spanning technology in home-based healthcare to work consciously to build and protect the trusting relationship in order to provide good healthcare.

\section{Methodological Consideration}

The data about relationships in present study was elicited from interview text where nurses were narrating about their experiences about encounters in home-based nursing care. During the narrations the nurses made detailed descriptions of the relationship and its importance for good nursing care at home. The interviewer followed the nurses' stories and asked clarifying questions without guiding them towards a specific focus on relationships [16]. However, it is obvious that the narrations contained limited experiences of harmful or negative relationships in home-based nursing care. This can be seen as a limitation and might have emerged if the nurses had received specific questions about these kinds of relationships.

In the analysis of present study the warp (main theme) and the weft (sub-themes) was used as a metaphor to show how core content of dimensions of relationship in nurses' narrations developed. A qualitative interpretation of text is always dependent, in part, on the researchers' theoretical orientation and other authors may have emphasized other parts of the contents of text or used another metaphor for synthesizing the findings. The authors are well-versed in the nursing literature and have extensive experience in the methodology. The authors have consciously used their theoretical orientation in nursing and their understanding of the text and discussed the different steps of the analysis thoroughly [15]. In addition, the rigor of the process was supported by using NVivo 9 computer program [18], which altogether strengthen the trustworthiness of the analysis [15].

The topic of the study relates to common human phenomenon and is therefore possible to transfer to other similar context in home-based care. The finding could be transferred in the manner of naturalistic generalization [38] where the reader interprets and determines which findings can be generalized to another context and also adds to previous knowledge. The transferability is also supported by the fact that it is supported in other nursing literature.

\section{CONCLUSION}

A trusting relationship is a prerequisite for good homebased nursing care whether it is based on face-to-face encounters or remote encounters through distance-spanning technology or a mix of both, and it is by nature an asymmetric relationship where the nurse has the responsibility to care for the person in need of care.

In order for nurses to build a trusting relationship in home-based nursing care they have to accept that they enter the home as a guest and communicate something about themself as the person in need of healthcare needs to know who is entering and visiting the home, or who is communicating through distance-spanning technology. The relationship in home-based nursing care requires conscious 
efforts from the nurse and a choice of a suitable level of the relationship when maintaining the relationship through home visits as well as through distance-spanning technology. The working context of home-based care is anticipated to change, with the introduction of new technology and revised templates of care. In this process nurses have to safeguard the possibilities of building trusting relationships with the persons in need of home-based care.

\section{CONFLICT OF INTEREST}

The authors confirm that this article content has no conflict of interest.

\section{ACKNOWLEDGEMENTS}

We would like to thank all nurses for their cooperation in this study. We are also grateful to Tarquin Shepherd for valuable language revision of the manuscript, and for the support received from the Department of Health Science, Luleå University of Technology, Sweden.

\section{REFERENCES}

[1] Meleis AI. Theoretical nursing: development and progress. 5th ed. Philadelphia: Wolters Kluwer Health/Lippincott Williams \& Wilkins 2011.

[2] Norberg A, Axelsson K, Rahm Hallberg I, et al. Omvårdnadens mosaik. [The mosaic of nursing]. Stockholm: Almqvist \& Wiksell 1992.

[3] Elstad I, Torjuul K. The issue of life: Aristotle in nursing perspective. Nurs Philos 2009; 10: 275-86.

[4] Fleischer S, Berg A, Zimmermann M, Wüste K, Behrens J. Nursepatient interaction and communication: a systematic literature review. J Public Health 2009; 17: 339-53.

[5] Kasén A. Den vårdande relationen. [The caring relationship]. Department of Caring Science, Abo: Abo Akademi 2002.

[6] Berg L, Berntsson L, Danielson E. Caring relationship in an outpatient clinic: balancing between vulnerability and dignity. Int $\mathrm{J}$ Hum Caring 2006; 10: 23-30.

[7] Attree M. Patients' and relatives' experiences and perspectives of 'good' and 'not so good' quality care. J Adv Nurs 2001; 33: 456-66.

[8] Løgstrup KE. Det etiska kravet. [The ethical demand]. Göteborg: Daidalos 1992.

[9] Granados Gámez G. The nurse-patient relationship as a caring relationship. Nurs Sci Q 2009; 22: 126-7.

[10] Walshe C, Luker KA. District nurses' role in palliative care provision: a realist review. Int J Nurs Stud 2010; 47: 1167-83.

[11] Hörberg U, Brunt D, Axelsson Å. Clients' perceptions of clientnurse relationships in local authority psychiatric services: a qualitative study. Int J Ment Health Nurs 2004; 13: 9-17.

[12] Iranmanesh S, Häggström T, Axelsson K, Sävenstedt S. Swedish nurses' experiences of caring for dying people: a holistic approach. Holist Nurs Pract 2009; 23: 243-52.

[13] Mok E, Chiu PC. Nurse-patient relationships in palliative care. J Adv Nurs 2004; 48: 475-83.

[14] Dahlberg K. Vårdlidande - det onödiga lidandet. [Care suffering the needless suffering]. Vard Nord Utvecki Forsk 2002; 22: 4-8.
[15] Berg BL. Qualitative research methods for the social sciences. $6^{\text {th }}$ ed. Boston: Pearson 2006.

[16] Kvale S, Brinkmann S. InterViews - learning the craft of qualitative research interviewing. $2^{\text {nd }}$ ed. Los Angeles: Sage Publications 2009.

[17] Sandelowski M. Qualitative analysis: what it is and how to begin. Res Nurs Health 1995; 18: 371-5.

[18] Richards L. Handling qualitative data: a practical guide. $2^{\text {nd }}$ ed. London: Sage 2009.

[19] Baxter LA. In: Montgomery BM, Ed. Content analysis. London: The Guilford Press 1991; pp. 239-54.

[20] Häggström T, Axelsson K, Norberg A. The experience of living with stroke sequelae illuminated by means of stories and metaphors. Qual Health Res 1994; 4: 321-37.

[21] Berg L, Danielson E. Patients' and nurses' experiences of the caring relationship in hospital: an aware striving for trust. Scand J Caring Sci 2007; 21: 500-6.

[22] Bell L, Duffy A. A concept analysis of nurse-patient trust. Br J Nurs 2009; 18: 46-51.

[23] Hagerty BM, Patusky KL. Reconceptualizing the nurse-patient relationship. J Nurs Scholarsh 2003; 35: 145-50

[24] de Raeve L. Trust and trustworthiness in nurse-patient relationships. Nurs Philos 2002; 3: 152-62.

[25] Hupcey JE, Penrod J, Morse JM, Mitcham C. An exploration and advancement of the concept of trust. J Adv Nurs 2001; 36: 282-93.

[26] Buber M. Jag och du. [Ich und Du]. Ludvika: Dualis 1990.

[27] Runquist C, Barbosa da Silva A. Relevansen för Martin Bubers dialogfilosofi för vårdvetenskap. [The relevance of Martin Buber's dialogue philosophy in health science]. Vard Nord Utvecki Forsk 2000; 20: 49-54.

[28] Fredriksson L, Eriksson K. The ethics of the caring conversation. Nurs Ethics 2003; 10: 138-48.

[29] Buber M. Distans och relation. [Urdistanz und Beziehung]. Ludvika: Dualis 1997.

[30] Ejneborn-Looi GM, Hellzén O. Nurses' perception of the relationship between themselves and the long-term psychiatric client - an interview study. Prim Care Community Psychiatr 2006; 11: 185-92.

[31] Bergum V, Dossetor JB. Relational ethics: the full meaning of respect. Hagerstown, Md.: University Pub. Group 2005.

[32] Öresland S, Määttä S, Norberg A, Jörgensen M, Lützén K. Nurses as guests or professionals in home health care. Nurs Ethics 2008; 15: $371-83$.

[33] Eriksson I, Nilsson K. Preconditions needed for establishing a trusting relationship during health counselling - an interview study. J Clin Nurs 2008; 17: 2352-9.

[34] Lévinas E. Etik och oändlighet: samtal med Philippe Nemo. [Ethics and infinity. Conversations with Philippe Nemo]. Stockholm Symposion, Brutus Östlings förlag 1988.

[35] Wälivaara B, Andersson S, Axelsson K. Views on technology among people in need of health care at home. Int J Circumpolar Health 2009; 68: 158-69.

[36] Milligan C, Roberts C, Mort M. Telecare and older people: who cares where? Soc Sci Med 2011; 72: 347-54.

[37] Szczepura A. Residential and nursing homes: how can they meet the challenge of an aging population? Aging Health 2011; 7: 87787.

[38] Stake RE. In: Denzin NK, Lincoln YS, Eds. Qualitative case studies. $3^{\text {rd }}$ ed. Calif.: Thousand Oaks Sage. 2005; pp. 443-66. 